\title{
Levo-transposition of the Great Arteries in an Adult Patient: Management Considerations and Treatment Strategy
}

Matthew R. Lozier ${ }^{1}$, Alexandra M. Sanchez ${ }^{1}$, John J. Lee ${ }^{2}$

1. Internal Medicine, University of Miami, Holy Cross Hospital, Fort Lauderdale, USA 2. Cardiology, Columbia University, Mount Sinai Medical Center, Miami Beach, USA

Corresponding author: Matthew R. Lozier, mr1160@miami.edu

\section{Abstract}

Levo-transposition of the great arteries (L-TGA) is a rare congenital heart anomaly associated with the increased risk of developing heart failure (HF) as well as complete heart block at a young age. Due to limited data regarding the treatment strategy in the adult L-TGA sub-population, shared medical decision-making should occur between the patient and a team of physicians. Clinical status, age, and associated cardiac lesions or rhythm disturbances can affect patient outcomes. These factors should be considered prior to pursuing a surgical versus a medicinal approach.

Categories: Cardiac/Thoracic/Vascular Surgery, Cardiology, Internal Medicine

Keywords: levo-transposition of the great arteries, systemic right ventricle, double switch operation

\section{Introduction}

Levo-transposition of the great arteries (L-TGA) is a rare congenital anomaly leading to progressive dysfunction of the systemic ventricle, which is a morphologic right ventricle (RV). These patients are at increased risk of heart failure (HF) as well as complete heart block at a younger age, and early preventative efforts should be made when possible [1]. We present a 37-year-old adult male with L-TGA and review management considerations as well as treatment strategies.

\section{Case Presentation}

A 37-year-old asymptomatic adult male with previously diagnosed L-TGA presented to the clinic to establish care. He reported normal development without cyanosis or functional limitation. On physical exam, III/VI holosystolic murmur and S4 were appreciated. The electrocardiogram demonstrated left axis deviation and $\mathrm{Q}$ waves in the early right precordial leads. Transthoracic echocardiogram demonstrated atrial to ventricular $(\mathrm{AV})$ and ventricular to arterial (VA) discordance consistent with corrected transposition of the great arteries, as seen in Figure 1. There was a restrictive perimembranous ventricular septal defect and moderate right ventricular dilation with decreased systemic right ventricular function. Following these findings, cardiac computed tomography angiography was performed to further assess the congenital anomaly, as seen

\section{(c) Copyright 2019}

Lozier et al. This is an open access article distributed under the terms of the Creative Commons Attribution License CC-BY 3.0, which permits unrestricted use, distribution, and reproduction in any medium, provided the original author and source are credited.

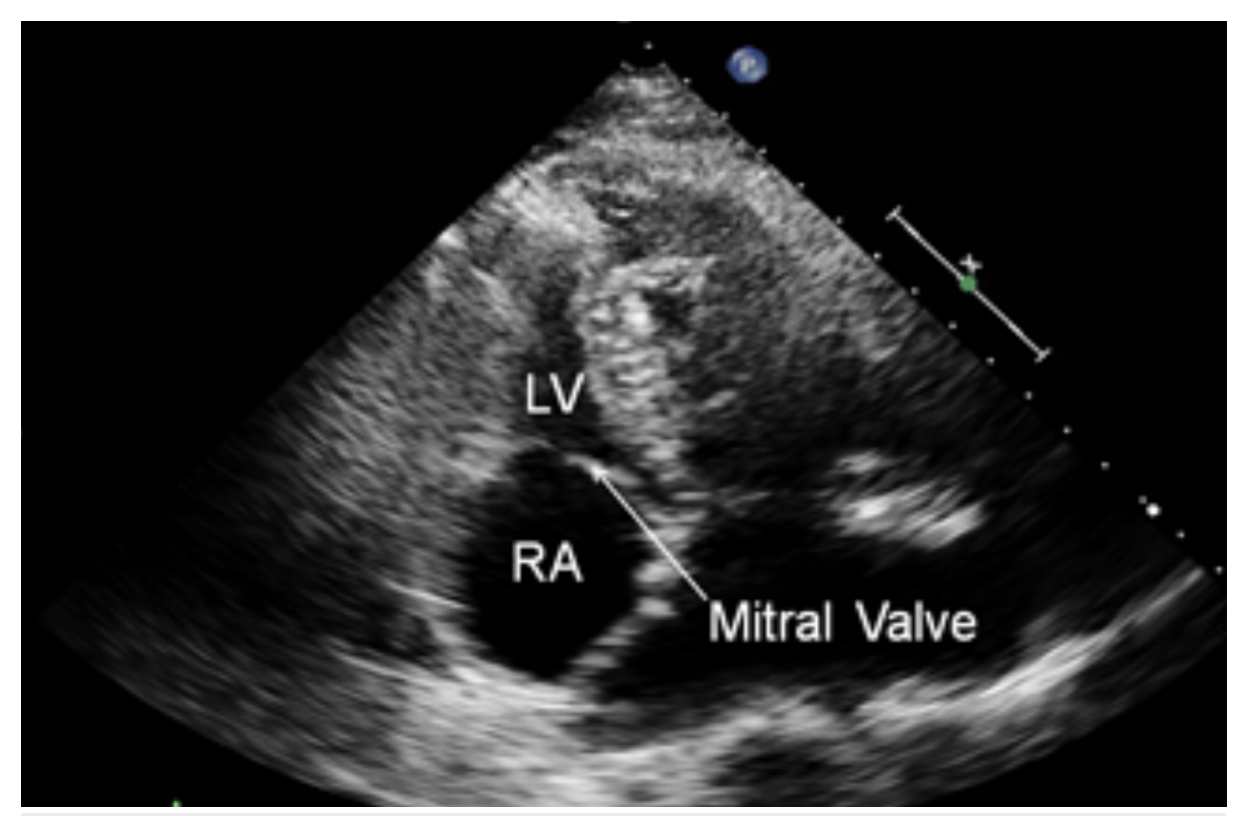




\section{Cureus}

\section{FIGURE 1: Transthoracic Echocardiogram}

Demonstrating atrial to ventricular discordance with the right atrium separated from the left ventricle by the mitral valve.
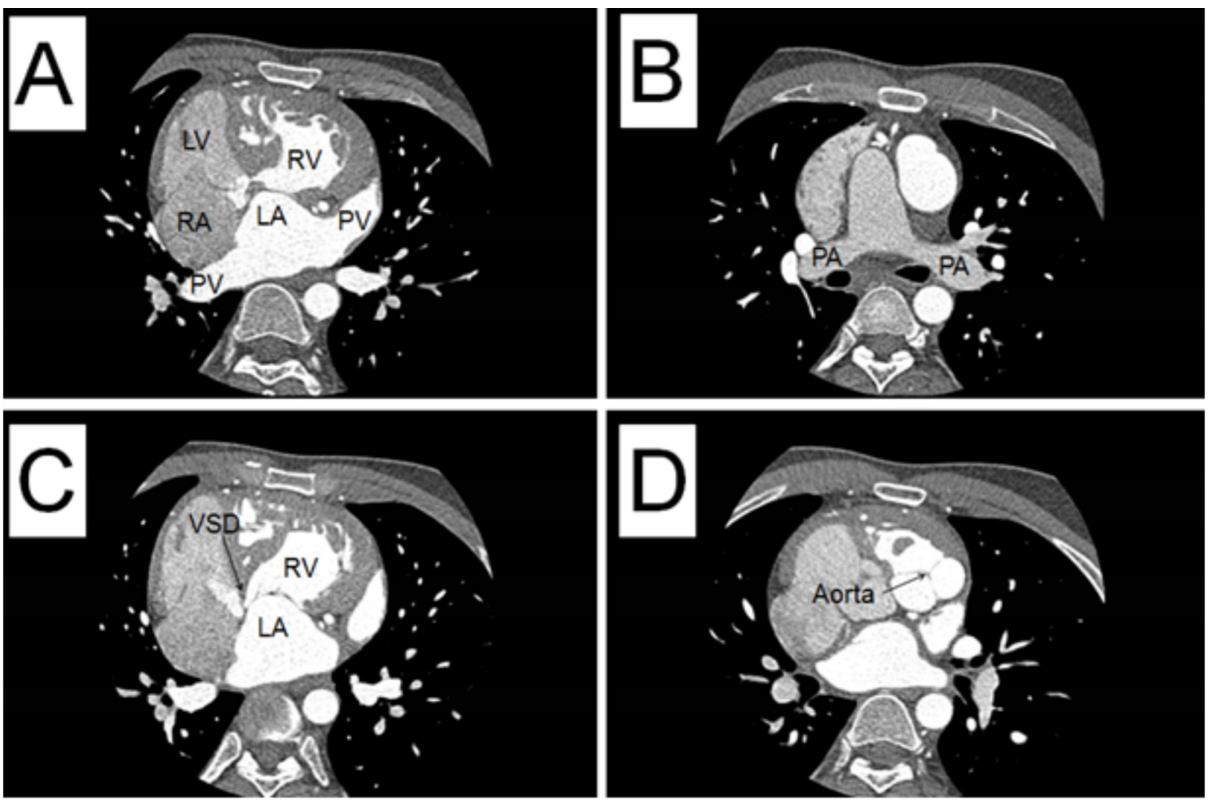

\section{FIGURE 2: Cardiac Computed Tomography Angiography}

Demonstrating the sagittal view of $A$. The right atrium (RA) connected to the left ventricle (LV). Contrast in the pulmonary vein (PV) filling the left atrium (LA) to the right ventricle (RV). B. The pulmonary arteries (PA). C. Contrast from the LA to the RV with a ventricular septal defect (VSD) noted. D. Contrast in the aortic valve, which is projecting to the side.

\section{Discussion}

L-TGA patients typically present with nonspecific HF symptoms at an early age due to the morphologic RV functioning as the systemic pump. Although there is increasing favor for performing a double switch operation (correcting AV and VA discordance, allowing the left ventricle to function as the systemic pump) in infants and young children with L-TGA, older teens and adults have not fared as well with this procedure [1 3]. Medical management is, therefore, the more widely accepted treatment strategy. For those patients who have significant systemic AV or VA valve insufficiency, prompt surgical intervention is required [4]. Unfortunately, from the medicinal perspective, there is a paucity of data on how best to treat patients with L-TGA after a certain age. Due to this limitation, therapies are often based on the 2017 updated American Heart Association guidelines for HF (Stage C) with some caveats.

The goal of treatment is to reduce afterload and slow remodeling in order to improve or mitigate RV dysfunction, as the RV is not built to sustain the role of the left systemic ventricle in the long term. The principle behind this strategy is to decrease the pressure on the wall of the RV during ejection, similar to the medical approach in HF. Two such agents that will reduce afterload and may slow the remodeling process include angiotensin-converting enzyme inhibitors and angiotensin receptor blockers (ACE-I/ARBs) [5-7]. In addition, $\beta$-blocker use in patients with systemic right ventricles demonstrated an increase in $\mathrm{EF}$ and smaller RV end-diastolic area at the four-month follow-up, implying reduced cardiac remodeling [8-9]. However, it is important to note that L-TGA patients have an associated risk of developing complete heart block, so these HF agents are used with caution unless an in-situ pacemaker is present [9]. While diuretics are used for symptomatic relief and use is based on the treating institutions' preference, digoxin and aldosterone antagonists have not shown clinical benefits [10-12]. After a detailed discussion with our patient, he was initiated on an ACE-I and $\beta$-blocker with plans for up-titration as tolerated. It must be noted that while the data above demonstrate some improvement in function of the systemic RV with regards to the use of $\beta$-blockers and ACE-I/ARBs, there is no proven mortality benefit noted.

\section{Conclusions}

Due to limited data in the adult L-TGA sub-population, medical management options are not wellsupported by evidence. Therefore, each case should be tailored to the individual being treated. Factors such 
as clinical status, age, and associated cardiac lesions or rhythm disturbances should be reviewed by specialists prior to shared medical decision-making with the patient.

\section{Additional Information \\ Disclosures}

Human subjects: Consent was obtained by all participants in this study. Conflicts of interest: In compliance with the ICMJE uniform disclosure form, all authors declare the following: Payment/services info: All authors have declared that no financial support was received from any organization for the submitted work. Financial relationships: All authors have declared that they have no financial relationships at present or within the previous three years with any organizations that might have an interest in the submitted work. Other relationships: All authors have declared that there are no other relationships or activities that could appear to have influenced the submitted work.

\section{References}

1. Filippov A, Del Nido P, Vasilyev N: Management of systemic right ventricular failure in patients with congenitally corrected transposition of the great arteries. Circulation. 2016, 134:1293-1302. 10.1161/CIRCULATIONAHA.116.022106

2. Van Praagh R, Papagiannis J, Grünenfelder J, Bartram U, Martanovic P: Pathologic anatomy of corrected transposition of the great arteries: medical and surgical implications. Am Heart J. 1998, 135:772-785.

3. Winlaw D, McGuirk S, Balmer C, et al.: Intention-to-treat analysis of pulmonary artery banding in conditions with a morphological right ventricle in the systemic circulation with a view to anatomic biventricular repair. Circulation. 2005, 111:405-411. 10.1161/01.CIR.0000153355.92687.FA

4. Mongeon FP, Connolly HM, Dearani JA, Li Z, Warnes CA: Ventricular function at the time of systemic atrioventricular valve replacement predicts long-term ventricular function. J Am Coll Cardiol. 2010, 35:A39.E376.

5. Winter MM, Bouma BJ, Groenink M, Konings TC, Tijssen JGP, van Veldhuisen DJ, Mulder BJM: Latest insights in therapeutic options for systemic right ventricular failure: a comparison with left ventricular failure. Heart. 2009, 95:960-963. 10.1136/hrt.2008.156265

6. Robinson B, Heise CT, Moore JW, Anella J, Sokoloski M, Eshaghpour E: Afterload reduction therapy in patients following intraatrial baffle operation for transposition of the great arteries. Pediatr Cardiol. 2002, 23:618-623. 10.1007/s00246-002-0046-2

7. Dore A, Houde C, Chan K, et al.: Angiotensin receptor blockade and exercise capacity in adults with systemic right ventricles: a multicenter, randomized, placebo-controlled clinical trial. Circulation. 2005, 112:2411-2416. 10.1161/CIRCULATIONAHA.105.543470

8. Bouallal R, Godart F, Francart C, Richard A, Foucher-Hossein C, Lions C: Interest of B-blockers in patients with right ventricular systemic dysfunction. Cardiol Young. 2010, 20:615-619. 10.1017/S1047951110000764

9. Doughan ARK, McConnell ME, Book WM: Effect of beta blockers (carvedilol or metoprolol XL) in patients with transposition of great arteries and dysfunction of the systemic right ventricle. Am J Cardiol. 2007, 99:704-706. 10.1016/j.amjcard.2006.10.025

10. Yancy CW, Jessup M, Bozkurt B, et al.: 2013 ACCF/AHA guideline for the management of heart failure: a report of the American College of Cardiology Foundation/American Heart Association task force on practice guidelines. J Am Coll Cardiol. 2013, 62:e147-239.

11. Rich S, Seidlitz M, Dodin E, et al.: The short-term effects of digoxin in patients with right ventricular dysfunction from pulmonary hypertension. Chest. 1998, 114:787-792.

12. Dos L, Pujadas S, Estruch M, et al.: Eplerenone in systemic right ventricle: double blind randomized clinical trial. The evedes study. Int J Cardiol. 2013, 168:5167-5173. 